\title{
LA CULTURA DE LA HOMOSEXUALIDAD: LECCIONES DESDE LOS RITOS DE «PASAJE»
}

\author{
Dula F. Pacquiao, EdD, RN, CTN \\ Associate Professor and Director, Transcultural Nursing \\ Institute and Graduaie Program \\ Kean University - Union, N]. USA \\ Mary Kay Carney, BA, BSN, RN \\ Staff Nurse, Pediatrics \\ Palisades General Hospital \\ New Jersey, USA
}

\section{RESUMEN}

Este trabajo describe la cultura de la homosexualidad: ritos de «pasaje».

Palabras clave: Antropologia y enfermeria. Transculturalismo.

\section{SUMMARY}

The culture of homosexuality: Lessons from Rites de Passage

Keywords: Nursing and anthropology. Transculturalism.

This work described the categories of rituals with successive and distinct moments in ritual time: separation, margin and aggregation. Found in all societies, these rites accompany every change of place, state, social position and age. These rites indicate and constitute transitions between relatively fixed or stable conditions or state (Turner, 1964). The life of an individual in any society according to van Gennep is a series of passages from one state to another i.e. age, occupation. Progression from one group to another are enveloped in ceremonies whose essential purpose is to enable the individual to pass from one defined position to another which is equally well-defined. Since the goal is essentially the same, the rituals of progression share similarities in the sense that they possess the same beginnings and ends. Human life, for instance, is made up of succession of predicta- ble stages from birth, puberty, marriage, parenthood, occupational achievement and death.

\section{RITOS DE PASAJE Y UMBRAL}

En su trabajo preliminar, «Rites of Passage», Arnold van Gennep (1960) describió tres categorías de ritos con periodos de tiempo sucesivos y distintivos en el tiempo que dura el ritual: separación, margen y agregación. Encontrandose en todas las sociedades, estos ritos acompanan a todo tipo de cambio de lugar, estado, posición social y edad. Estos ritos indican y constituyen transiciones entre estados relativamente fijos o estables (Turner, 1964). La vida de un individuo en una sociedad según van Gennep es una serie de pasajes de un estado a otro p.e. edad u ocupación. La progresión de un grupo a otro está envuelta en ceremonias en las cuales esencialmente su propósito es habilitar a un individuo para pasar de un estado definido a otro igualmente definido. Puesto que la meta es en esencia la misma, los ritos de progresión comparten similitudes en el sentido de que poseen los mismos principios y fines. La vida humana, por ejemplo, está compuesta por una sucesión de etapas predecibles desde el nacimiento, pubertad, matrimonio, paternidad, logros profesionales y muerte.

La primera fase de diferenciación consiste en un cambio del comportamiento simbólico con un significado de desapego del individuo o del grupo 
tanto desde un punto fijo en una estructura social como en una serie de condiciones culturales. Durante el periodo umbral de intervención o en el límite de éste, el estado del individuo es ambiguo puesto que él o ella pasa a través de un terreno que tiene pocos o ningún atributo del anterior o al que va a pasar. En la tercera fase de incorporación o agregación, el camino se ha recorrido y el individuo se encuentra de nuevo en un estado estable o definido, en acorde con sus derechos y obligaciones, y sujeto a ciertas normas y conductas claramente definidas por el estado o posición (Turner, 1964). Los rituales en este contexto son de transformación y las ceremonias asociadas con cada cambio de estado o de posición sirven para confirmar el estatus del individuo dentro de un grupo o una sociedad.

Mediante el uso de sus observaciones de los rituales de iniciación, Victor Turner ha ampliado el concepto de límite o periodo umbral. Describe al individuo durante este periodo como estructural y fisicamente invisible, y como a alguien al que ya no se le puede clasificar. Según Turner (1964) el liminalpersonae (neophite, initiate) está entre lo uno y lo otro, ni aquí ni alli y culturalmente definido como ha sido o será. En contraste con otras fases, este periodo está falto de referencias simbólicas creando una ambiguedad en la posición o estado social del individuo. La ambiguedad innata es una característica de esta fase que permite nuevas categorías de ideas o relaciones que surgen durante la fase de transición de un estado desestructurado a otro estructurado del ser.

Mary Douglas (1968) está de acuerdo en que las nociones de contaminación y tabú no son más que reglas que protegen a las personas y a las sociedades de la ambigüedad y de la disonancia. Crean y preservan barreras de protección para asegurar el orden moral y social. El orden se mantiene creando unos rituales para esquivar esta ambiguedad o indiscreción. Mantiene que lo que no está claro y puede ser contradictorio según las definiciones sociales se considera ritualmente como sucio. Por esto, el liminal personae es universalmente considerado como algo contaminante para los demás, los cuales nunca han sido protegidos de él. Son recluidos parcial o totalmente del terreno de los estados o estatus culturalmente definidos u ordenados. En esencia existen fisicamente pero no socialmente; los ocultan, por lo tanto su existencia es una paradoja social, un escándalo.

Los rituales de iniciación son de limpieza, de purificación mediante los cuales se consigue que el liminal personae esté limpio, sagrado y merecedor de entrar en pleno derecho con un estatus privilegiado como miembro de una sociedad. A los iniciados se les pide que hagan un juramento para preservar y mantener las categorías y las normas asociadas al nuevo estado. El iniciado entra en un nuevo estado de comportamientos, roles y estatus bien definidos. Una vez más, su existencia se hace visible a la vez que su realidad social y personal confirma y refuerza los unos a los otros.

\section{PERSPECTIVA HISTÓRICA DEL UMBRAL DE LA HOMOSEXUALIDAD}

Los eventos históricos asociados a los gays y lesbianas documentan una interacción explosiva y altamente negativa entre la sociedad y su establecimiento institucional. La homosexualidad forma parte de la experiencia humana desde los registros históricos más antiguos. El Informe Kinsey publicado en 1948 describía la homosexualidad como un continuum desde la heterosexualidad exclusiva hasta la homosexualidad exclusiva, con un alto grado de variación en la población. El informe revelaba que en su estudio el 10\% de los hombres se describian a sí mismos como exclusivamente homosexuales (NMALGH, 1996). En los Estados Unidos la mayor parte de la población no prestó atención a la existencia de una comunidad gay y lesbiana hasta que iuvo lugar el incidente 
Stonewall Inn en la ciudad de Nueva York en el que oficiales de la policia asaltaron un bar gay en la calle Christopher en Junio de 1969. Los asaltos eran hechos comunes anteriormente, pero lo que lo hizo destacable fue el hecho de que los clientes devolvieron el ataque a lo que continuó un fin de semana de disturbios. Esto fue considerado como el comienzo del movimiento de los derechos de los gays.

\section{El primer crimen por odio documentado} contra un hombre gay en la época colonial fue el asesinato del intérprete de francés, Guillermo, quien fue matado por los españoles en Florida por ser un traidor y un sodomita. La primera ley que contemplaba la homosexualidad fue promulgada en 1610, en la colonia de Virginia en la que se castigaba con la pena de muerte la sodomía. En 1624, esta pena fue aplicada a Richard Corneish, el contramaestre del barco Ambrose, a quien se le dijo que había sido ahorcado por "sodomía» con muy pocas pruebas contra él. Otras colonias y más tarde, otros estados, siguiendo el ejemplo establecido en la Colonia de Virginia de promulgar leyes estableciendo que una relación de mutuo acuerdo entre dos adultos (del mismo sexo) se penalizase con la pena capital. No fue hasta 1961 en que Illinois se convirtió en el primer estado que abolió sus leyes contra las relaciones homosexuales consentidas (NMALGH, 1996).

En 1924, se fundó la primera organización gay en Illinois. Este grupo, la Sociedad para los Derechos Humanos, publicó la primera revista para la liberación de los gays de todo el país. La Sociedad Mattachine se formó en Los Ángeles en 1951. Jugó un importante papel en la creación de lo que más tarde sería el movimiento de liberación gay. El piquete de 1965 de la Casa Blanca por los Miembros de la Sociedad Mattachine para protestar por las prácticas discriminatorias de empleo, marcaron la primera protesta gay del país. En 1955, Las Hermanas de Bilitis, la primera organización lesbia- na de los Estados Unidos, comenzó a publicar la revista La Carrera. Hoy, muchas organizaciones tales como Campaña de los Derechos Humanos y la Fundación Lambda de la Defensa Legal, así como muchas personas de forma individual, continúan trabajando en pro de la igualdad de derechos dentro de la legalidad para las lesbianas y los gays.

Hasta 1973, la American Psychiatric Association clasificaba la homosexualidad como un desorden mental. La homosexualidad fue considerada como un desorden por la American Medical Association hasta 1994, momento en el que se retiraron los «desordenes relacionados con la orientación sexual» de su política oficial. Estas clasificaciones de enfermedad y de desórdenes psiquiátricos se utilizaban para justificar terapias crueles para el tratamiento de la homosexualidad. Algunos ejemplos sobre los tipos de tratamientos usados en hombres gays eran la castración y las vasectomías alrededor de 1890, hipnosis y lobotomías desde 1900 hasta 1960, análisis e internamiento desde 1920 hasta 1970, terapia de aversión y electroshock hasta los 70 y abstinencia desde 1890 hasta el presente. Mientras que la homosexualidad ya no se considera un desorden, los prejuicios todavía existen dentro de los estamentos médicos.

A pesar de los avances cientificos que vinculan, la homosexualidad a la biología, la creencia de que la homosexualidad es una elección y condición prevenible permanece. Un número de estudios sobre gemelos idénticos separados en el nacimiento y que crecieron en diferentes entornos ha hallado una alta correlación entre ellos. Un estudio sobre hermanos realizado por Bailey y Pillard halló un $52 \%$ de correlación entre gemelos idénticos homosexuales, un $22 \%$ entre gemelos fraternales y un $10 \%$ de correlación para adoptados o hermanos no genéticos. Un estudio realizado por Dean Hamer en el National Institute of Health comparó el ADN de 40 pares de hermanos homosexuales y se halló una marca genética similar en la región 
xq28 del cromosoma $X$. Estos estudios sugerían con mucho peso un componente genético de la homosexualidad (Hamer \& Copeland, 1994).

Al estudiar los cerebros de hombres gays y heterosexuales que habian muerto por complicaciones del SIDA, el neuroanatomista Simon LeVay (1993) halló una medida diferente entre los dos grupos en el INAH3, una estructura dentro del hipotálamo a la que se la asocia con el «comportamiento sexual masculino típico». Este estudio sugiere que hay algunas diferencias biológicas asociadas con la homosexualidad.

Aunque la homosexualidad está comenzando a ser aceptada como un modo de vida con una probable base biológica y genética, en muchos estados, todavía es ilegal que dos adultos del mismo género mantengan relaciones fisicas de mutuo consentimiento. Es legal, en cambio, en muchas zonas, la discriminación de gays y lesbianas en temas de alojamiento y empleo. No es poco frecuente que las familias repudien a los miembros gays o lesbianas de la familia una vez que se revela o se descubre su preferencia sexual.

Una informante lesbiana relató este incidente acerca de un compañero de trabajo. Ambos eran. responsables de los cuidados de un paciente gay, Michael, en un hospital. Una noche el novio de Michael llamó para saber como se encontraba. Michael estaba profundamente dormido cuando la informante fue a su habitación por lo que le dijo a su novio que le pediría a Michael que le llamase cuando despertara. Antes de que terminase su turno, la informante le pidió a su colega que le dijese a Michael que su novio había llamado cuando se despertara. La compañera asintió con un tono de voz normal pero susurró cuando menciono su novio.

La informante supuso que la necesidad de la compañera de susurrar provenía del interior... se derivaba de su creencia de que el hecho de ser gay es algo de lo que hay que avergonzarse o que es algo demasiado grosero como para discutir o hablar de ello. Si el paciente hubiese sido una mujer, la palabra novio no la habria dicho de la misma manera. Bajó el tono de su voz debido a su propia incomodidad y no por el deseo del paciente de conf dencialidad.

Las formulaciones sobre el umbral y la contaminación hechas por Turner y Douglas respectivamente, ayudan a comprender las reacciones de la sociedad hacia los homosexuales a lo largo de la historia. La homosexualidad es una no-categoría en una sociedad con unos estados claramente diferenciados de ser un hombre, una mujer, una madre o un padre. La supervivencia de las sociedades está enraizada en la reproducción heterosexual apoyada en rituales con un propósito específico. La homosexualidad con propuestas de géneros de roles y biológicos ambiguos amenazan las clasificaciones y categorias sobre las que están construidas las realidades fisicas y sociales. Los gays y las lesbianas no son clasificables en las propuestas de categorías ordenadas de roles sociales y biológicos. Sus umbrales no tienen una capacidad previsible de paso a un nuevo estado de categoría lógico y preexistente. Ningún ritual puede transformar su estado a una categoría confirmable de ser masculino o femenino. Principalmente amenazan las bases reproductoras de la sociedad y su supervivencia. Tal y como se demuestra a lo largo de la historia, la amenaza percibida por la sociedad se puede manifestar a un nivel individual o institucional bajo las formas de la discriminación, violencia y rechazo

\section{LA SUBCULTURA HOMOSEXUAL}

Una característica distintiva de la cultura es su lenguaje y sus símbolos. Esto se demuestra dentro de la subcultura gay y lesbiana americana a través del uso de expresiones que comunican experiencias que no son comunes a la cultura popular. Algunas expresiones han evolucionado debido a una necesidad de privacidad. Por ejemplo, la pala- 
bra family (familia) se utiliza dentro de la comunidad gay para hablar del hecho de ser gay, especialmente en sitios públicos en donde las palabras gay o lesbiana podrían atraer una atención no deseada y un posible abuso (por ejemplo, muchos de mis clientes son de la familia, pero lo mantienen en secreto). En ocasiones, el simple hecho de cambiar el pronombre de él a ella o viceversa es suficiente para evitar una atención indeseada.

Cuando alguien oculta su condición a la familia o a algunos amigos, podría ser necesario retirar cualquier signo que le pudiese delatar como gay que pudiese estar presente en su hogar antes de la visita de los padres, familiares o de amigos heterosexuales. Esto pude implicar quitar libros, fotografias y objetos de decoración y también puede implicar el preparar un dormitorio más, para aparentar que uno de los miembros de la pareja habita en él. De forma jocosa se pueden referir uno a esto como un arreglo, pero puede ser estresante el construir una fachada que se puede caer de golpe ante una visita sorpresa en una salida del armario no planificada.

A la vez que salir del armario es una expresión que ha pasado a ser de uso común para expresar que se le dice a otra persona cuál es la orientación sexual de uno, tiene un significado en un nivel más complejo dentro de la comunidad. La expresión salir del armario por uno mismo se refiere a que uno llega a darse cuenta de que es o debería ser gay. Esta experiencia puede ser muy positiva, ya que se le da un nombre a muchos pensamientos y sentimientos confilsos. Lo más frecuente es que sea una experiencia negativa, ya que produce miedo la posible pérdida del amor y la aceptación de los amigos y de la familia y produce miedo las sanciones contra la homosexualidad de la cultura predominante. Salir del armario por uno mismo es el primer paso del proceso, que debe ser seguido por un incremento de la aceptación personal antes de que uno pueda ser capaz de salir del armario para la familia o los amigos (O'Neil \& Ritter, 1992).

Existen muchos símbolos dentro de la cultura gay. El más popular es la bandera del arcoiris. Fue diseñado originalmente por el artista Gilbert Bakerin, para el Desfile del Día de la Libertad de los Gays y las Lesbianas. La primera bandera del arcoiris tenía ocho franjas y estaba cosida y teñida a mano. Los colores simbolizaban componentes de la comunidad: rosa intenso para el sexo, el rojo para la vida, el naranja para la curación, el amarillo para el sol, el verde para la naturaleza, el turquesa para el arte, el añil para la harmonía y el violeta para el espíritu. En 1979, la bandera se produjo en cadena y debido a problemas de fabricación el rosa intenso y el turquesa se eliminaron y el azul real sustituyó al añil (NMALGH, 1996). La versión de seis colores de la bandera del arcoiris fue reconocida por el Congreso Internacional de Fabricantes de Banderas y hoy en día es un signo ampliamente reconocido del orgullo y la diversidad de los gays y de las lesbianas y a menudo se expone como una etiqueta adhesiva en los parachoques. La bandera del arcoiris ha inspirado una variedad de símbolos tales como los aros de la libertad (unos aros con los colores del arcoiris metalizados y anodizados que se llevan en cadena). Los colores del arcoiris se pueden encontrar expuestos en muchos lugares tales como alfombrillas de ordenadores, collares de mascotas, utensilios domésticos y tatuajes.

El triángulo rosa es un símbolo cuyas raíces se remontan hasta la 2." Guerra Mundial en Alemania. Los homosexuales estaban entre uno de los múltiples objetivos de los Nazis, aunque la información a menudo se omite de las crónicas históricas. Entre 1933 y 1945 se estima que entre 25.000 y 50.000 hombres se enviaron a prisión y más tarde a campos de concentración, acusados de infringir la ley alemana, que prohibia las fantasias homosexuales y los actos sexuales así como los besos o los abrazos. En los campos de concentra- 
ción, cada prisionero llevaba un símbolo para designar su crimen: triángulos rojos para los prisioneros políticos, dos triángulos amarillos formando la estrella de David para los judios y triángulos rosas para los homosexuales. La clase más baja de los prisioneros eran los judios homosexuales, que llevaban una Estrella de David amarilla y un triángulo rosa superpuestos. Los prisioneros homosexuales eran tratados más severamente tanto por los guardias como por los otro prisioneros. Los grupos de liberación gay de los 70 comenzaron a usar el triángulo rosa como un símbolo del movimiento por los derechos de los homosexuales, dirigiendo la atención hacia la opresión y la persecución en el pasado y en el presente (NMALGH, 1996).

La comunidad homosexual masculina fue uno de los primeros grupos afectados por la crisis del SIDA, en los Estados Unidos. Esta experiencia ha conllevado el desarrollo de muchos simbolos culturales e indicativos de grupos de redes de apoyo para el-bienestar emocional, espiritual y fisico. Las lesbianas y los gays han contribuido en todas las áreas del arte, el cine, la música y la comedia. La comunidad artística ha hecho contribuciones en la lucha contra el SIDA. Estos grupos y artistas, asi como muchos actores de forma individual, han usado lazos rojos y han apoyado públicamente a los patrocinadores de fondos de ayuda contra el SIDA para así llamar la atención de la opinión pública.

Una contribución de los gays es el estilo de humor o sátira conocida como camp (campamento-amanerado) se basa en la exageración de la androginia. Dentro de la comunidad gay, el término que con más frecuencia se utiliza para referirse a los gays que asumen un estilo femenino rimbombante con el propósito de entretener, como por ejemplo en ciertos espectáculos teatrales es drag (arrastrar-ir vestido de mujer). El camp también se puede contemplar como una forma especial de mecanismo de defensa psicológica para la uautodefensa, especialmente en el pasado, cuando los gays podian usar expresiones creativas y mordaces para reirse de sí mismos, creando un espectáculo de comedia fuera de lo que podria ser objeto de critica o abuso por parte de los intolerantes" (NMALGH, 1996). También existe una tradición camp entre las lesbianas, con un ejemplo de actualidad como es la humorista Lea Delaria.

Una marcha por el orgullo es una celebración pública en forma de desfile de lesbianas y de gays con el fin de proclamar el orgullo y la unidad de las personas homosexuales. La mayor marcha por el orgullo tiene lugar durante el último fin de semana del mes de junio en la ciudad de Nueva York, en conmemoración de la rebelión de Stonewall. En 1994, el 25. aniversario de la rebelión, congregó a gays y lesbianas de todo el mundo en Nueva York. Muchas otras capitales y ciudades de todo el mundo también celebraron marchas por el orgullo y festivales durante todo el mes de Junio. Las marchas por el orgullo o los desfiles, no son habitualmente un evento aislado. Habitualmente al final de la marcha o del desfile, hay un festival con entretenimientos y puestos de venta de comida y todo tipo de objetos de recuerdo. Los clubes y las organizaciones patrocinadoras bailan durante la tarde previa a la marcha o durante la noche de la marcha de tal forma que la comunidad homosexual se puede reunir durante todo un fin de semana de celebraciones. El evento proporciona salud espiritual y mental a través de sus aspectos de unidad, orgullo y autoestima. Hay una mayor aceptación de la diversidad en los eventos por el orgullo gay que en la mayor parte del resto de encuentros públicos.

Los bares solían ser los únicos lugares a los que los homosexuales podian ir para poder sentirse libres con respecto a su sexualidad y poder encontrarse con otros homosexuales. Hoy los bares y los locales de baile continúan siendo la válvula 
social de escape para muchos, especialmente los jóvenes gays y lesbianas de la misma forma en que lo es para muchos jóvenes adultos heterosexuales. Debido al incremento de la atención en la salud en los Estados Unidos, y debido al incremento de la atención en la bebida, la conducción y el abuso del alcohol, muchos miembros de la comunidad patrocinan actividades sociales que excluyen el uso del alcohol y el tabaco en los bares. También van en aumento los grupos que prestan una mayor atención en las actividades al aire libre y en actividades deportivas. Alcohólicos Anónimos patrocina encuentros entre gays y lesbianas de los que en muchos actos de hermandad y actividades sociales se ha incrementado la eliminación del alcohol.

Puesto que cada persona homosexual o lesbiana funciona bajo las reglas diarias de la cultura dominante, es natural y saludable que se reúnan juntos en una subcultura. El compartir la carga de las adversidades y abusos cotidianos así como el compartir el júbilo de las celebraciones de la dignidad y el orgullo gay, sirve para fortalecer a cada miembro de la comunidad y a unir a la comunidad como un todo.

Los intentos tanto de los miembros gays o lesbianas de la comunidad así como de las personas que les apoyan para conseguir identificar e institucionalizar los rasgos culturales del grupo minimizan la existencia marginal de los homosexuales en la sociedad. A diferencia de otros grupos con una identidad evidentemente definida por características biológicas, el lenguaje y la localización geográfica, la ausencia de rasgos claros incrementa la ambiguedad de la homosexualidad. La ambiguedad tiene dos propósitos opuestos. Por un lado, proporciona una red de seguridad a aquellos que no quieren o no se sienten preparados para salir del armario. Para aquellos que han decidido salir del armario, la ambigüedad se convierte en una lucha persistente para definir la identidad de uno frente a los demás mediante el uso de símbolos o de ras- gos al margen de sus características fisicas o inherentes.

Una informante lesbiana nos proporcionó la siguiente anécdota. Tras un semestre de grandes logros en los estudios en medio de un mar de problemas personales y laborales, su compañera le animó a que dedicase más tiempo a su afición favorita, hacer edredones acolchados. Salió y compró materiales caros de la tienda. Dentro de su emoción, ella le dijo al dependiente de la tienda que su pareja le había recompensado por sus logros dándole el gusto de practicar su afición del acolchado. El dependiente respondió, espero que él tenga muchos niños que puedan disfrutar esto es el futuro. La suposición de que ella tenía un compañero masculino fue inesperada, a pesar de que ella había salido del armario, era ambivalente en el modo de reaccionar ante esta situación. Debido a la ausencia de rasgos claros, el hecho de ser homosexual puso a esta informante en un punto límite, en el que se le pedía, para mantener su consistencia, que decidiese si debía revelar y afirmar su personalidad a los extraños.

\section{LA MARGINALIDAD EN LAS RELACIONES HOMOSEXUALES}

Existen aspectos especiales en las relaciones entre gays y lesbianas presentes dentro de la comunidad gay y lesbiana que no existen en la sociedad heterosexual. Debido a que las relaciones entre gays y lesbianas no pueden ser legalmente reconocidas por el matrimonio, hay menos apoyo y aceptación social. Los matrimonios entre parejas heterosexuales disfrutan de muchos más derechos y privilegios que las parejas homosexuales quienes deben haber estado viviendo juntos de forma oficial durante muchos años. Las parejas heterosexuales comienzan su relación con la creencia de que durará para siempre, a pesar de las estadisticas de divorcios. La comunidad gay carece de modelos de rol de parejas gay que hayan permanecido juntas 
durante muchos años. Las parejas gay que se establecen tienden a ser de una edac avanzada y están asociadas a otras parejas de su edad fuera de la vida social gay que es la que atrae a la multitud de jóvenes. Por contra, los modelos de rol de las parejas heterosexuales están fácilmente al alcance en los padres y los abuelos con unas relaciones de larga duración que mantienen un contacto cercano con los miembros de la familia de varias generaciones (Berzon, 1989).

Mientras que las vacaciones y las reuniones familiares pueden ayudar a la unión de las familias, suelen suponer un reto para las parejas gay. Si los miembros de la familia originaria no aceptan plenamente la homosexualidad de otro miembro, se les permite no aceptar la relación así como a su compañera/o. Las vacaciones son el momento en el que las familias se reúnen y tales ocasiones pueden provocar conflictos entre la lealtad a la familia de origen y la lealtad a la pareja (Berzon, 1989).

Un problema adicional al que se pueden llegar a enfrentar se produce cuando una relación gay no está reconocida ni por la familia ni por los compañeros de trabajo. Personas que pueden llevar una larga y feliz relación pueden ser tratados como solteros por los otros amigos heterosexuales, y tachársele como de un solterón en potencia. Las lesbianas pueden darse cuenta de que dan pena por ser una vieja solterona (Berzon, 1989).

La falta de modelos de rol y de apoyo de los miembros de las familias y de la sociedad en general hace que el mantener una relación estable entre homosexuales se pueda convertir en algo problemático. La mayor parte de los gays que ya han pasado la veintena dirán normalmente, que buscan una relación estable y duradera. La tendencia es comenzar la relación que se establece de una manera excesivamente rápida, sin que haya un cortejo real, o un tiempo para conocerse. Una vez que la relación se torna complicada, las parejas prefieren romper en lugar de trabajar en el desarrollo de la relación. La búsqueda de consejo profesional por parte de las parejas homosexuales va en aumento.

La comunidad gay está trabajando por sus derechos para conseguir la legalización del matrimonio. Hay un gran número de derechos y responsabilidades asociadas al matrimonio que se les deniega a los gays y a las lesbianas que mantienen. una relación legal duradera. El 3 de diciembre de 1996, la corte de Hawai dictaminó que el estado se había equivocado al mostrar un estado inamovible de interés en pro de la continua discriminación de las parejas de un mismo sexo. El estado apeló la decisión de inmediato. No se puede expedir ninguna licencia de matrimonio a parejas de un mismo sexo mientras que este caso esté bajo apelación. La decisión final se espera que sea emitida por la Corte Suprema de Hawai hacia el final de 1997. De forma anticipada a esta decisión, la Ley de la Defensa del Matrimonio fue promulgada por el Congreso y firmada por el Presidente Clinton. Esta ley permite a los estados que promulguen leyes que permitan que un matrimonio sea legal en un estado e ilegal en otro. Las parejas gay no se podrían casar en Hawai para más tarde regresar a su propio estado y ser considerados como legalmente casados si su estado de origen no elige reconocer el matrimonio (Red Wing \& Buermeyer, 1997). La cobertura de los seguros de salud no son tan fácilmente alcanzables para las lesbianas y los gays así como para sus hijos. Las parejas gays y lesbianas de larga duración, con una relación legal no se pueden casar, y son muy pocas las compañias que extenderán la cobertura de los cuidados de salud a la pareja de un empleado. Puesto que las mujeres suelen trabajar en puesto de empleo peor pagados que los hombres, para la mayoría de las lesbianas no se pueden permitir un seguro de salud.

\section{VIOLENCIA Y HOMOSEXUALIDAD}

De la misma manera en que los abusos físicos se dan lugar en muchas relaciones heterosexuales, 
los malos tratos también tienen lugar en las relaciones entre lesbianas y gays. Es menos probable que la policía o los profesionales de la salud atiendan un acto de violencia doméstica que se esté desarrollando ya que la relación en la que está existiendo la violencia no está reconocida. La opinión pública tiende a asociar la violencia doméstica con las parejas heterosexuales con una desigualdad en cuanto a fuerza entre el hombre y la mujer. Un hombre gay que está sufriendo la violencia doméstica puede que no tenga ningún lugar al que acudir, y una lesbiana puede que no sea aceptada en una casa de acogida cuando la que golpea es otra mujer. Cuando la policía se encuentra implicada puede que no haga nada en absoluto o que encarcelen a la persona equivocada, suponiendo que la persona más grande es la que abusa (Douris, 1997).

Son muy pocos gays los que pueden afirmar que nunca han experimentado algún tipo de gay basing (dar una paliza a un gay), en forma de abuso verbal o fisico. Las víctimas de crímenes violentos puede que no sean sinceras con respecto a los motivos del ataque o sobre los detalles del crimen con la policía o con el personal de la sala de urgencias. En su libro, Ocho Balas, Claudia Brenners (1985) narra los sucesos en una acampada cuando a ella y a su compañera les disparó en ocho ocasiones un desconocido que se había percatado de que eran una pareja de lesbianas. Mi mecanismo de autoprotección como lesbiana nunca dejó de funcionar, ni siquiera en los peores momentos de la tragedia Mientras que continuaba sangrando, mientras que ellos eran la única ayuda que tenía, oculté a la policia tanto mi relación con Rebeca como la motivación que yo sabia que habia existido para el ataque. Continué haciéndolo cuando el riesgo por mi vida ya habia concluido. Lejos de sentir que no cooperaba, oculté información cuando el terror ya habia pasado. Alguien acababa de dispararnos por ser lesbianas. ¿Cómo iba a permitir que ni un sólo hombre desconocido más conociera este hecho?

\section{CUESTIONES DE SALUD}

Hay algunas preocupaciones especiales dentro de la comunidad. En 1981, el CDC comunicó la información acerca del creciente número de casos de neumonía debida al pneumocystis carinni entre hombres homosexuales. También hubo un aumento del número de casos de un tipo de cáncer muy poco frecuente, el sarcoma de Kaposi. Los investigadores que comenzaron a vincular estas dos enfermedades con hombres homosexuales, la bautizaron incorrectamente como Desorden de la Inmunidad Relacionado con Gays e intentaron asociarlo al empleo de nitrato de amilo. Hacia el final de 1981 la enfermedad también se comenzó a observar entre los consumidores de drogas intravenosas (NMALGH, 1996).

La reacción de la comunidad gay fue rápida e interesada. En 1982, se formó la Crisis de la Salud de los Hombres Gay. Esta organización sin ánimo de lucro con base en la ciudad de Nueva York consiguió fondos para proyectos de investigación y formó a voluntarios para educar a la comunidad y responder a las preguntas y preocupaciones sobre la enfermedad. Por contra, el gobierno y la comunidad heterosexual reaccionó de forma mucho más lenta a la crisis del SIDA ya que la habían contemplado como una enfermedad de gays y de adictos a las drogas. En 1985, la entonces Secretaria de Salud y Servicios Humanos, Margaret Hecler, afirmó: Debemos conquistar el SIDA antes de que afecte a la población heterosexual. Jerry Falwell, en 1983 se refirió al SIDA como el juicio de Dios, mientras que a los niños y a los receptores de transfusiones de sangre que resultaron infectados de SIDA se les denominaba las víctimas inocentes. Muchos percibieron el SIDA como una justificación para prejuzgar y discriminar a los gays (NMALGH, 1996).

El virus del SIDA no se aisló hasta 1984, y la primera prueba de detección estaba disponible en 1985. La AIDS Coalition to Unlesh Power 
(Coalición del SIDA para Desencadenar Poder) se fundó en 1987 como un grupo de acción directa, de confrontación. La primera protesta del ACT UP's tuvo lugar en el distrito federal de la ciudad de Nueva York en la que se pedía a la administración Reagan que permitiese la aprobación de nuevos medicamentos para la lucha contra el SIDA. Fue durante ese mismo año cuando el AZT, el primer agente antiviral contra el SIDA, se aprobó por la FDA.

El SIDA ha supuesto un impacto dramático en las vidas y en las relaciones de muchas de las personas de dentro de la comunidad. De forma similar, ha supuesto un impacto profundo en las prácticas de salud y en los estilos de vida culturales. Los gays movilizaron sus recursos para formar centros y clinicas de tratamiento, para crear organizaciones para generar fondos para los proyectos relacionados y para desarrollar unas redes de apoyo para las personas con SIDA y para aquellos que habian perdido a una persona amada debido a la enfermedad. Películas, arte, música, literatura e incluso comedias han servido todas ellas como válvulas de escape para el dolor y la pérdida sufrida por la comunidad gay.

La comunidad de gays y lesbianas han sido los responsables de llamar la atención de la opinión pública americana hacia la crisis del SIDA así como de conseguir los fondos para los programas de investigación y de tratamiento durante la crisis. Organizaciones tales como DIFFA, Design Industries Foundation Fighting Aids (Fundación de Lucha contra el SIDA de las Industrias de Diseño) y Visual Aid: Artists for AIDS Relif (Ayuda Visible: Artistas para el Auxilio del SIDA) han proporcionado ayuda financiera para la investigación del SIDA así como la asistencia de las personas con SIDA. La comunidad gay, a través de organizaciones tales como Gay Men's Health Crisis ha promocionado la educación sobre prácticas de sexo seguro tanto dentro de la comunidad como para el público heterosexual. Literatura, información, condones gratuitos y guantes de látex están disponibles en muchos encuentros públicos y sociales de gays.

La comunidad lesbiana se ha interesado recientemente en la investigación y el tratamiento del cáncer de mama. Muchas lesbianas tienen un riesgo superior de padecer cáncer de mama. La comunidad lesbiana ha establecido un énfasis creciente en el sexo seguro entre mujeres, con el fin de evitar enfermedades de transmisión sexual, incluyendo el SIDA.

La Asociación de Médicos Gays y Lesbianas está disponible para derivar a cualquiera de los mil seiscientos gays y lesbianas que practican la medicina a lo largo de Norte América, a los individuos que se puedan sentir más cómodos con un doctor gay.

\section{RITUALES DE SOLICITUD DE INCORPORACIÓN}

A pesar de los logros que han conseguido los gays y las lesbianas en cuanto al reconocimiento y la tolerancia social, se necesitan más esfuerzos para acelerar su incorporación al grueso de la sociedad. Se necesitan más investigaciones y una mayor expansión de los hallazgos que contemplen la base biológica de la homosexualidad. La discusión abierta de los resultados de las investigaciones por parte de la comunidad científica prestará una mayor credibilidad a toda esta información. El reconocimiento de una base biológica de los comportamientos homosexuales previenen la formación de séquitos de persona que culpabilizan a la víctima y además obtienen la expiación. Aleja a la sociedad del mito de la homosexualidad y la acerca a la elección de un estilo de vida. La vinculación de la homosexualidad a la biología abre la puerta de un mayor número de proyectos científicos sobre el fenómeno y permite la confirmación de las experiencias de los homosexuales. 
Los homosexuales y sus preocupaciones y problemas relacionados con la salud deberían formar parte del programa de estudios de cualquier profesión relacionada con la salud. La homosexualidad per se necesita ser estudiada desde una perspectiva diferente a la del SIDA o cualquier otra enfermedad relacionada con ella. El hecho de ser gay o lesbiana comporta un riesgo psicológico, social y cultural que en ocasiones tiene como consecuencia una crisis emocional. La experiencia de la homosexualidad tiene lugar en varias fases, cada una de las cuales está cargada de una buena dosis de confusión emocional y profundos riesgos personales. A diferencia de otros tipos de transición en la vida, el proceso de la salida del armario de los homosexuales no se anuncia como un proceso en el que uno va a formar parte ni de la familia ni de la sociedad. En contraste a otros pasajes de la vida, el salir del armario en definitiva no tiene como resultado una transición a una categoría de aceptación social dentro de la estructura social. Por lo tanto, un adolescente homosexual puede hallarse fácilmente en un estado constante de estrés agudo, tensión y ante una crisis potencial.

Los profesionales de la salud se puedan encontrar fácilmente con quejas psicosomáticas de los estados psicológicos que son de riesgo e inaceptables y que se pueden manifestar fácilmente como quejas de seguridad de tipo somático. Al carecer de una red de sistemas de apoyo, los profesionales de la salud son las personas que con más facilidad tendrán un primer contacto con el sistema de apoyo de cuidados de fuera de la familia del individuo y de los amigos. La clarificación de los valores así como el tomar consciencia por uno mismo es esencial para desarrollo de profesionales de la salud que cuiden sin uzgar y a quienes puede que se les requiera para servir de mediador entre el individuo y su familia y al mismo tiempo jugar un papel clave e el apoyo tanto del individuo como de su familia.
El curriculum debería consistir en un proceso de conocimiento de la homosexualidad, sus expresiones culturales, su lenguaje y sus símbolos. Una toma de conciencia del contexto sociocultural de la homosexualidad que proporcione un grado de empatía de los profesionales de la salud hacia los gays y las lesbianas. Cuidados culturalmente competentes para los homosexuales es una expectativa de cualquier proveedor de cuidados. La anticipación de los riesgos en los cuidados de la salud necesita unirse con una genuina defensa y sensibilidad hacia el individuo. Una informante lesbiana af rmó que el hecho de ir al ginecólogo para que le realizase un examen se convirtió en una experiencia de autonegación más que de autoaf rmación. Tanto el médico como el resto del equipo tienden a asumir que el hecho de ser mujer no va asociado a la maternidad o a mantener una actividad sexual con un hombre. El hecho de que los profesionales eviten formular suposiciones universales en cuanto al género de las personas es una labor que se debe dirigir desde que se entra en la escuela. Al comunicarse con los clientes, los profesionales de la salud deberían utilizar un lenguaje que minimizase las clasificaciones o las categorizaciones universales de las personas. Para decirlo de otra manera, esto es equivalente a crear una base de expectativas y estereotipos.

El conocer a los grupos de apoyo disponibles para los clientes homosexuales es de vital importancia cuando se prestan cuidados a individuos que fácilmente pueden sufrir el rechazo de los familiares, de los amigos o del grupo de iguales. Los profesionales de la salud deberían in más allá de una simple llamado a estas redes de apoyo y averiguar cuáles son los diversos servicios que ofrecen. La exposición de los profesionales de la salud a estos grupos les aclimatará a la cultura de la homosexualidad y les permitirá realizar recomendaciones apropiadas a sus clientes. 
Tal y como resaltaba van Gennep, Turner y Douglas, el problema asociado a la homosexualidad está en la sociedad y en la cultura de origen. Los esfuerzos por llevarles al grupo principal de la sociedad pasa por institucionalización de su cultura y de sus símbolos homosexuales. La responsabilidad de la institucionalización recae en la participación y en la aceptación de los grupos profesionales cuyas acciones e ideas influyen ampliamente sobre los otros. Al desmitificar la homosexualidad se generarán menos recelos y menos miedos hacia estos grupos. Al dar información y al mostrar habilidades actualizadas al público en general servirá para iluminar a otros sectores de la sociedad acerca de los principios del humanismo aplicables a todas las personas sin tener en cuenta su orientación sexual.

\section{REFERENCIAS}

Berzon, B. (1989). Permanent partners, building gay and lesbian relationships that last. New York: Page.
Brenner, C., \& Ashll.ey, H. (1995). Eight bullets, one woman's story of surviving anti-gay violence. Ithaca, New York: Firebrand.

Douglas. M. (1968). Pollution. In D. L. Sills (ed.), International encyclopedia of the social sciences: Volume XII (pp.336-341). NY: Crowell Collier and MacMillan.

Douris, A. (1997, September). Battering the closet door. Girlfriends, 18.

Hamer, D. H., \& Copeland, P. (1994). The science of desire: the search for the gay gene and the biology of behavior New York: Simon \& Schuster.

LEVAY, S. (1993). The sexual brain. Cambridge, MA.: MIT Press. (NMALGH) The National Museum and Archive of Lesbian and Gay History. (1996). The Gay Almanac New York: Berkeley. O'Neitl, C., \& RitTER, K. (1992). Coming out within, stages of spiritual awakening for lesbians and gay men, San Francisco: Harper.

RED WING, D., \& BUERMEYER, N. (1997, Spring). The state of our unions. HRC Quarterly. 10-11.

TURNER, V. (1964). Betwixt and between: The liminal period in rites de passage. The Proceedings of the American Ethnological Society. Symposium on new approaches to the study of religion (pp.4-20). Seattle: University of Washington Press.

Van Gennep, A. (1960). The rites of passage. Translated by M. B. Vizedom and G. L. Caffee. 1llinois: University of Chicago Press.

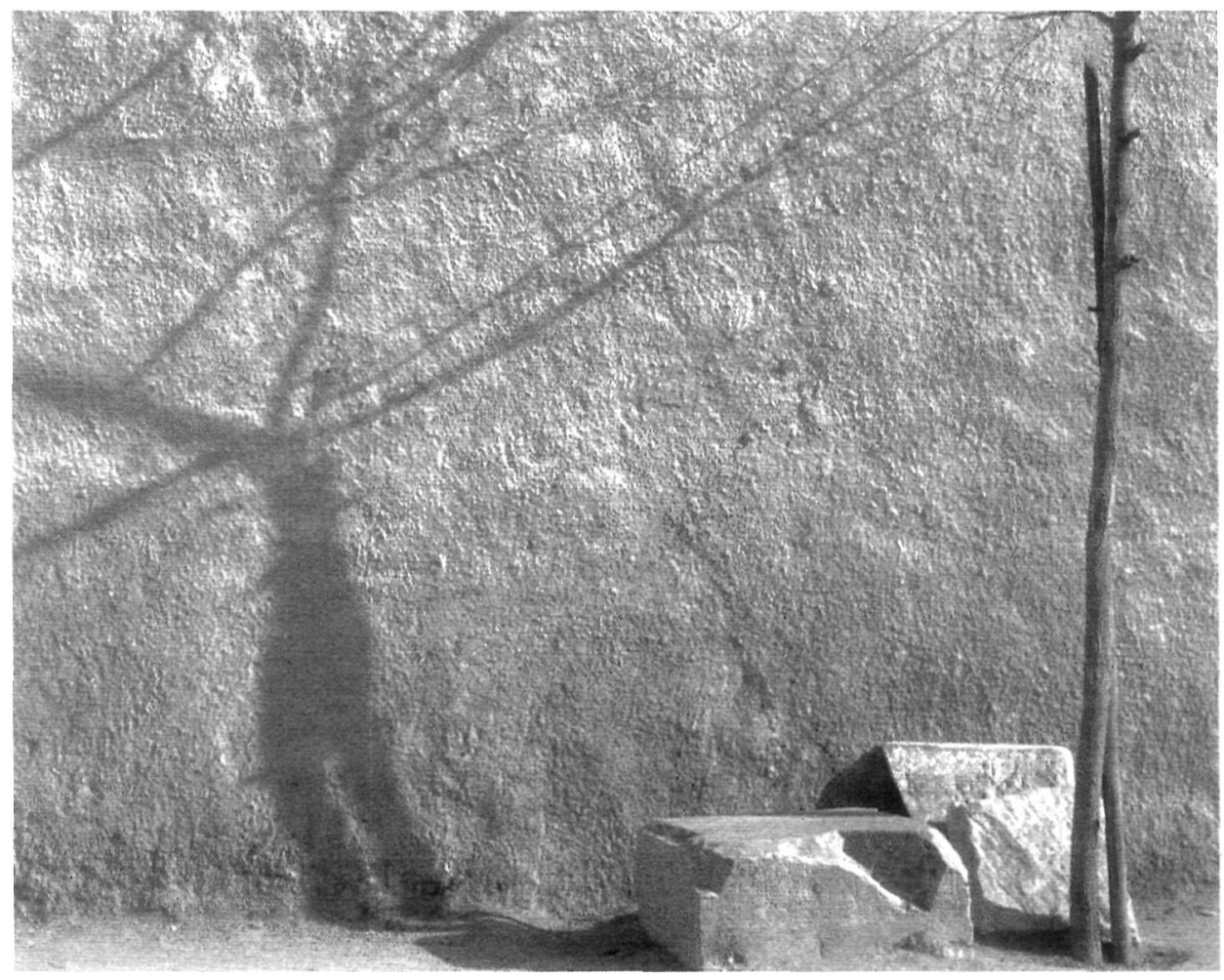

